\title{
The performance of investment newsletters ${ }^{\text {is }}$
}

\author{
Jeffrey F. Jaffe ${ }^{\mathrm{a}, *}$, James M. Mahoney ${ }^{\mathrm{b}}$ \\ ${ }^{a}$ The Wharton School, University of Pennsylvania, Philadelphia, PA 19104, USA \\ ${ }^{\mathrm{b}}$ The Federal Reserve Bank of New York, New York, NY 10045, USA \\ Received 23 February 1998; received in revised form 11 September 1998
}

\begin{abstract}
This paper analyzes the recommendations of common stocks made by the investment newsletters followed by the Hulbert Financial Digest. We conclude that, taken as a whole, the securities that newsletters recommend do not outperform appropriate benchmarks. Our data provide modest evidence that the future performance of a newsletter is related to its past performance, when performance is measure by raw returns. Evidence of persistence vanishes, however, when performance is measured by abnormal returns. We find little, if any, evidence of herding, i.e., cross-sectional dependence of recommendations, across newsletters. Newsletters tend to recommend securities that have performed well in the recent past. Finally, newsletters with poor past performance are more likely to go out of business. (C) 1999 Elsevier Science S.A. All rights reserved.
\end{abstract}

JEL classification: G11; G14

Keywords: Investment newsletters; Stock selection; Performance measurement

* Corresponding author. Tel.: 215-898-5615; fax: 215-898-6200.

E-mail address: jaffe@wharton.upenn.edu (J.F. Jaffe)

The authors have benefited from the comments of a seminar at the Federal Reserve Bank of New York, the Brown Bag Lunch Workshop of the Finance Department of the Wharton School at the University of Pennsylvania, and the suggestions of an anonymous referee. The authors thank Mark Hulbert of the Hulbert Financial Digest for his data, as well as for helpful advice and suggestions. The financial support of the Rodney L. White Center of the Wharton School is gratefully acknowledged. The views expressed in this paper are not necessarily the views of the Federal Reserve Bank of New York or the Federal Reserve System. 


\section{Introduction}

Over the years, financial economists have studied in depth the performance of mutual funds, pension funds, and investment advisors. Researchers have typically focused on two related questions: Do funds, on average, outperform appropriate benchmarks, and do individual funds exhibit persistence in their performance? Brealey and Myers (1996, p. 330) provide a credible summary of these studies when they say, 'The gains by professional fund managers appear to no more than cover the expenses of managing the portfolios', and 'It turns out that there were some predictably bad managers, whose performance was 2 to 3 percent a year worse than their colleagues'. But among the remaining managers the differences in relative performance were far less significant'.

While mutual funds manage the money of many individuals, other individuals manage their own money, some with the help of professional investment advice. Investment newsletters are one source of this advice. In the United States, hundreds of newsletters make recommendations on asset allocation and/or on individual securities. In addition, publications, seminars, and television shows frequently ask newsletter publishers to share their recommendations.

In contrast to the large number of papers on mutual funds, there has been a dearth of academic studies on newsletters, most likely because of the difficulty in obtaining data. However, Hulbert Financial Digest (HFD) has been collecting newsletter recommendations since 1980, and the publisher, Mark Hulbert, made the data through 1996 available to us.

While newsletters provide security recommendations across many asset classes, as well as advice on asset allocation, our study focuses only on the recommendations of common stocks. A recent paper by Graham and Harvey (1996) has studied recommendations of asset allocation but not stock recommendations. In addition to shedding light on a previously ignored segment of the investment community, research on newsletters has at least two other benefits. Even if mutual funds do not beat appropriate benchmarks, they still may provide low-cost diversification for the small investor. Since newsletters only provide recommendations, however, a finding of zero differential performance would be more damning to newsletters than to funds. Second, because mutual funds can terminate mid-period, studies of these funds have been subject to the criticism of hindsight bias. By contrast, our study should not be subject to this criticism. Once a recommendation is made, we follow it forward in time, even if the newsletter has ceased publication in the meantime.

Our paper is structured as follows. Section 2 provides descriptive statistics on newsletters. We discuss our methodology for measuring performance in Section 3. Section 4 gives results on the overall performance of newsletter recommendations. We examine performance persistence, herding, and survivorship in Sections 5-7, respectively. Concluding comments appear in Section 8. 


\section{Description of data}

Hulbert Financial Digest (HFD), itself a newsletter, has been following the recommendations of other newsletters since 1980. Since HFD subscribes to all the newsletters that it follows, it obtains recommendations in 'real time'. HFD maintains a database of all the recommendations it has ever received from other newsletters. Because of this real-time feature, the database is not subject to hindsight or other biases. ${ }^{1}$

The HFD database classifies newsletters into two types. Some newsletters recommend portfolios specified in terms of the number of shares of each security to be held. Other newsletters recommend portfolios specified in terms of the percentage holdings of each security. HFD also has data on newsletters that provide a list of recommended stocks but no percentage allocation among them. Our study does not employ this dataset, since such newsletters may merely list a set of recommendations in each issue without continuity across issues.

Many individual newsletters provide a number of separate portfolios. For example, a single newsletter may present a low-risk portfolio, a medium-risk portfolio and a high-risk portfolio. Another newsletter may show a $\$ 50,000$ portfolio, a $\$ 200,000$ portfolio and an $\$ 800,000$ portfolio. (Approximately onefourth of the newsletters in our sample provide recommendations for multiple portfolios.) Since the separate portfolios in a single newsletter tend to hold similar stocks, we follow the performance of the combined portfolio of a newsletter, which we define as the equal-weighted combination of the newsletter's separate portfolios.

The number of newsletters in our sample rose steadily from 18 in 1980 to 96 in 1996, the last year in our sample. Newsletters appear to be relatively long-lived, with over $2 / 3$ of our sample lasting for at least six years.

Table 1 provides descriptive data on our sample. The first line shows the median number of common stocks recommended per newsletter from the end of 1980 to the end of 1996 . The median is quite constant over our sample period. These numbers appear to be considerably below the number of common stocks in typical equity mutual funds. Since newsletters frequently specialize in one sector of the market, however, their recommendations should not be viewed as a complete portfolio.

The second line of Table 1 presents the average beta of recommended stocks across newsletters. Betas of individual stocks are measured against the valueweighted CRSP index. We measure the beta of a stock at the end of a particular year using the prior 48 monthly observations. The beta of a newsletter's portfolio is the value-weighted average of the betas of the individual stocks in

\footnotetext{
${ }^{1}$ A more extended discussion of hindsight bias appears at the beginning of Section 3 .
} 


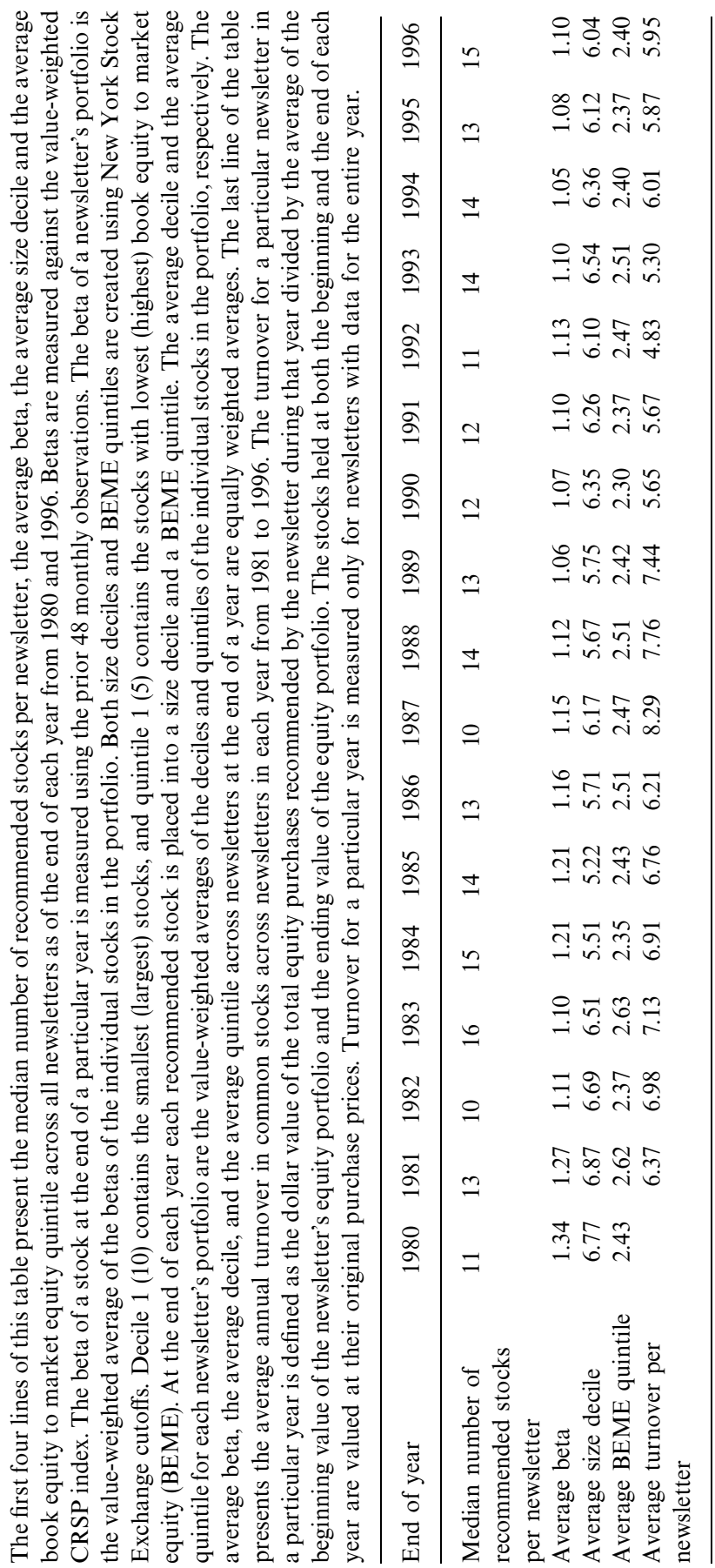


the portfolio. We then obtain an equally weighted average of the betas of the individual newsletters. The average beta is somewhat over one in each of the 17 years in our sample period. Except for the first two years, the average beta exhibits relatively little movement over time.

The next two lines of Table 1 show the average size decile and average book equity to market equity (BEME) quintile of recommended stocks across newsletters. At the end of each year, we create both size deciles and BEME quintiles from all common stocks on the NYSE. Decile 1 (10) and quintile 1 (5) contain securities with the smallest (largest) market capitalizations and the lowest (highest) BEME ratios, respectively. At the end of each year, each recommended stock is placed into a size decile and a BEME quintile. The average decile and average quintile for each newsletter's portfolio are the value-weighted averages of the deciles and quintiles, respectively, of the individual stocks in the portfolio. The average decile and the average quintile across newsletters at the end of the year are equally weighted averages.

The average size decile across all newsletters ranges between 5 and 7, with an average of 6.16 over the 17 years of our sample period. This number can be interpreted in two ways. On the one hand, if stocks of all sizes on NYSE were represented equally in newsletters' recommendations, the average size decile would be 5.5. On the other hand, the value-weighted average of the size deciles across all stocks listed on the NYSE, AMEX, and NASDAQ turns out to be 8.9 over our sample period. Thus, newsletters recommend stocks that are slightly larger than the average of those in an equally weighted portfolio but far smaller than the average of those in a value-weighted portfolio.

If stocks of all book-to-market ratios were equally represented in newsletters' recommendations, the average BEME quintile would be 3. The average BEME quintile is below 3 in each of the 17 years, indicating that newsletters tend to select growth stocks over value stocks.

The last line of Table 1 shows the average annual turnover of equity holdings per newsletter. We define the turnover for a particular newsletter in a particular year as the dollar value of the total equity purchases recommended by the newsletter during that year divided by the average of the beginning value of the newsletter's equity portfolio and the ending value of the equity portfolio. The stocks held at both the beginning and the end of each year are valued at their original purchase prices. We measure turnover over a given year only for newsletters that were in existence for the entire year.

The average annual turnover is high, with numbers ranging between 4.83 and 8.29 over our sample period. (Since we did not have a full year of data in 1980, we did not calculate turnover for that year.) We obtain numbers similar to those in Table 1 when (a) total sales of common stock are used instead of total purchases in the calculation of turnover and when (b) turnover is calculated on a monthly basis and then annualized. (To put this into perspective, Carhart (1997) estimates that, over the January 1962-December 1993 period, the average 
annual mutual fund turnover was 0.773 .) Yet, these results are not necessarily surprising. Newsletters commonly publish on a monthly or even a weekly basis, with some providing a hotline with continual access as well. A high level of new recommendations may be needed to justify both the frequency of publication and the cost (often a few hundred dollars) of subscription.

\section{Methodology}

Our dataset provides us with the complete record of recommended holdings of the newsletters covered by the Hulbert Financial Digest (HFD). The dataset appears to be without hindsight bias. $H F D$ records recommendations from a given issue of a newsletter on the date that $H F D$ receives the issue. In addition, a few newsletters provide 'hotline' recommendations by telephone. HFD's policy is to make repeated phone calls to these newsletters to receive the recommendations on the day the newsletter issues them. Our sample includes these hotline recommendations as well. From time to time, a newsletter will state that it is going out of business and that the current issue is the last one. HFD also records these recommendations but follows the recommendations only to the end of the calendar month in which $H F D$ receives this notification. We employ the same convention. HFD also contacts newsletters that appear to have ceased publication without prior notification. If the newsletter's publisher states that publication has indeed ceased, $H F D$ will follow the last set of recommendations to the end of the month in which the contact occurred. If the publisher indicates that the newsletter expects to resume publishing, $H F D$ keeps the last set of recommendations in force.

In this section, we calculate returns on the portfolios recommended by newsletters. For each issue of a newsletter, our analysis assumes that securities are 'purchased' at closing prices on the day that HFD receives the issue. These holdings are maintained until a new issue of the newsletter is received. For each newsletter, we calculate the return on the newsletter's portfolio for each day. The daily returns are compounded for each calendar month, yielding a monthly return. This formulation implicitly assumes that cash dividends from an individual stock are reinvested throughout the portfolio, rather than back into the individual stock. As mentioned in Section 2, individual newsletters frequently have a number of portfolios. The monthly return across all the portfolios in a newsletter is simply the equal-weighted average of the monthly returns on the different portfolios within the newsletter. We refer to this average as the monthly return on the newsletter's recommended portfolio.

We compare this monthly return to a benchmark portfolio, which is formed as follows. At each month-end over the period from 1980 to 1996, we rank by size all common stocks on the New York Stock Exchange (NYSE) that are in Stock Price File of the Center for Research in Security Prices at the University of 
Chicago (CRSP) to create ten size-based deciles. Within each decile, all securities on the NYSE that are in both CRSP and COMPUSTAT are ranked by book equity to market equity (BEME) to form five BEME quintiles. Although the breakpoints for the deciles and quintiles are determined only from securities on the NYSE, we place all securities in CRSP into one of these 50 portfolios. For each security recommended as of date $t-1$, we select a control security that has a price closest to that of the recommended security at the end of the previous month among all stocks that are in both the same size decile and the same BEME quintile as the recommended security. If a recommended security is not in COMPUSTAT, so that there is no way to place that security in a BEME portfolio, we use a size-based match alone. If CRSP does not provide the number of shares outstanding for a particular recommended stock, we drop that stock from the sample for the following calendar month.

The daily return on a portfolio of control securities is created in a manner analogous to the daily return on a portfolio of recommended securities. In particular, we point out above that recommended securities change with each new issue of a newsletter. In our methodology, securities in the control portfolio change with the recommended securities.

As with the recommended portfolio, daily returns on the control portfolio are compounded, yielding a monthly return. The abnormal return for the recommended portfolio of newsletter $n$ over month $t, A R_{n t}$, is simply the difference between the return on the recommended portfolio and the return on the control portfolio. This approach follows Barber and Lyon (1997). However, as a check, we have replicated some of our results by subtracting the return on a size-andBEME-matched control portfolio from each recommended stock, yielding similar results to those from our main methodology.

Next, we calculate an equally weighted, average abnormal return in calendar month $t$ across all newsletters as

$$
\overline{A R}_{t}=\frac{1}{N} \sum_{n=1}^{N} A R_{n t}
$$

where $N$ is the number of newsletters in existence at the beginning of month $t$.

The average monthly abnormal return $(\overline{A M A R})$ across our entire sample period is:

$$
\overline{A M A R}=\frac{1}{T} \sum_{t=1}^{T} \overline{A R}_{t}
$$

where $T$ is the number of calendar months in our sample. Since we have data from July 1980 to December 1996, T equals 198.

We use the portfolio method of Jaffe (1974) and Mandelker (1974) to assess statistical significance. Specifically, for each newsletter, we form a portfolio comprising long positions in the stocks recommended to be held as of the 
beginning of month $t$ and equal short positions in the control stocks. We next form a portfolio across all newsletters at the beginning of each calendar month consisting of equal weights in the above portfolios of the individual newsletters. For each calendar month, we calculate the standard deviation of returns on this portfolio across newsletters, $s_{t}$, from the previous 48 monthly returns. The standardized abnormal return, $S A R_{t}$, in calendar month $t$ is $\overline{A R}_{t} / \mathrm{s}_{t}$. The $t$ statistic across all calendar months is $1 / \sqrt{T} \sum_{t=1}^{T} S A R_{t}$, where $T$ is the number of calendar months in our sample.

\section{Results on performance measurement}

The overall performance of our sample of newsletters is shown in Table 2. The first row of the table shows that the average monthly abnormal return $(\overline{A M A R})$ is 0.00031 (3.1 basis points), which is statistically indistinguishable from zero. This number suggests that, taken as a whole, newsletters do not outperform their respective benchmarks. The results are consistent with a large body of academic evidence suggesting that mutual funds and other institutional investors, taken as a whole, do not have special forecasting ability. The results presented here are on a before-cost basis. Following the advice of newsletters would result in substantial transaction costs and therefore in underperformance relative to passive investment strategies.

The mean monthly geometric return is often used as a measure of long-run performance. Over our sample period, this return is 0.01324 for the sample of newsletters, 0.01287 for the sample of control firms, and 0.01257 for the Standard and Poor's 500 Index with reinvested dividends. The outperformance of newsletters here is similar in magnitude to the value of $\overline{A M A R}$ mentioned above.

The turnover numbers in Table 1 are high. Perhaps newsletters present their best ideas in each issue, while expecting subscribers to trade less frequently. We examine an alternative strategy in which any stock recommended at the beginning of the first month of our sample period, July 1980, is held for six months if the stock is removed from the newsletter's portfolio within six months. Another portfolio is recommended at the beginning of the next month, and once again we buy and hold for six months. We repeat this procedure each month over our sample period. The $\overline{A M A R}$ from this strategy is -0.00060 , with a $t$-value of -0.47 . We also consider this buy-and-hold strategy when the minimum holding period for a stock is 12 months rather than six months. The $\overline{A M A R}$ from this strategy is -0.00045 , with a $t$-value of -0.29 . Thus, the result that newsletters do not perform significantly differently from their control portfolios appears robust to different methodologies. 
Table 2

Average monthly returns for various portfolios of newsletters

Daily returns are calculated for the portfolio of recommended stocks of each newsletter. For each recommended security, a control security of similar size, book-to-market ratio, and price is selected. Daily returns for control portfolios are also calculated. For each newsletter daily returns are compounded to yield monthly returns. The abnormal monthly return for each newsletter is the difference between the monthly return for its portfolio of recommended stocks and the monthly return for its control portfolio.

Monthly abnormal returns across newsletters are calculated by weighting each newsletter equally according to Eq. (1). Average monthly abnormal returns, $\overline{A M A R}$, are calculated according to Eq. (2). $t$-values are calculated according to the portfolio approach of Jaffe (1974) and Mandelker (1974). Our sample runs from July 1980 to December 31, 1996.

In Panel B, at the end of every month, all securities on the NYSE are ranked by their book-to-market ratios and placed into one of five quintiles. Quintiles 4 and 5 are the high group, quintile 3 is the medium group, and quintiles 1 and 2 are the low group. Each recommended security is placed into one of these three groups based on its book-to-market ratio. In Panel C, recommended securities are placed into one of three groups based on size. The approach in Panel C is analogous to that in Panel B.

$\begin{array}{llll}\begin{array}{l}\text { Average monthly } \\ \text { raw return }\end{array} & \begin{array}{l}\text { Average montly } \\ \text { abnormal return }\end{array} & t \text {-value } & \begin{array}{l}\text { Number of } \\ \text { calendar months }\end{array} \\ (\overline{A M A R}) & \end{array}$

Panel A. Performance of all stocks recommended by newsletters
0.01510
0.00031
0.38
198

Panel B. Performance of recommended stocks classified by book-to-market ratio

$\begin{array}{lrrrr}\text { High } & 0.01521 & 0.00040 & 0.95 & 198 \\ \text { Medium } & 0.01341 & -0.00100 & -0.34 & 198 \\ \text { Low } & 0.01601 & 0.00303 & 2.01 & 198\end{array}$

Panel C. Performance of recommended stocks classified by size

$\begin{array}{lrrrr}\text { Large } & 0.01551 & 0.00140 & 0.60 & 198 \\ \text { Medium } & 0.01567 & 0.00096 & 1.18 & 198 \\ \text { Small } & 0.01485 & -0.00082 & -0.80 & 198\end{array}$

Panel B presents the performance of recommended stocks classified by the book-to-market ratio. At the end of every month, all securities on the NYSE are ranked by their book-to-market ratios and placed into one of five quintiles. Quintiles 4 and 5 form the high group, quintile 3 is the medium group, and quintiles 1 and 2 are the low group. We place each security recommended by a newsletter at date $t$ into one of these groups based on its book-to-market ratio at the end of the previous month. 
As can be seen, the performance of both the high group and the medium group is insignificantly different from zero. By contrast, the performance of the low book-to-market group is both economically and statistically significant. Thus, the results indicate that newsletters are better able to predict the performance of growth stocks than the performance of value stocks.

Panel $\mathrm{C}$ presents the performance of recommended stocks by size. At the end of every month, all securities on the NYSE are ranked by size and placed into one of five quintiles. Quintiles 4 and 5 are the large group, quintile 3 is the medium group, and quintiles 1 and 2 are the small group. We place each security recommended by a newsletter at date $t$ into one of these three groups based on its size at the end of the previous month. As can be seen, there appears to be no abnormal performance for any of the three rows in Panel $\mathrm{C}$. The insignificant performance for small stocks is particularly noteworthy, because it is generally alleged that mispricing and lack of information is more prevalent for these stocks. It is not obvious why newsletters appear to be better at selecting low book-to-market stocks than at selecting small stocks.

\section{Persistence}

Researchers have frequently examined the persistence of mutual fund performance, and we now examine persistence for our sample of investment newsletters. At the end of each year, we rank all newsletters by the average monthly raw returns of their recommended portfolios over the previous 12 months. We then place the newsletters into five quintile portfolios based on this past performance and calculate the average monthly raw returns on these quintiles for the next 12 months. In addition, the average correlation between the performance of a quintile over the past 12 months and the performance of the quintile over the subsequent 12 months is calculated. We also repeat the procedure using abnormal returns in both the selection period and the performance period instead of raw returns. Finally, we redo our tests for both raw returns and abnormal returns; this time we rank newsletters at the end of each year based on the performance over the past 30 months but still follow the performance of newsletters forward for 12 months.

The first (second) column in Panel A of Table 3 shows average monthly raw returns (abnormal returns) over a 12-month performance period; newsletters are also ranked by average monthly raw returns (abnormal returns) over a 12month selection period. The average correlation of the quintiles is 0.393 when we use raw returns, but the average correlation coefficient is only 0.009 when we use average monthly abnormal returns. The right-hand side of Panel A presents results when the selection period is 30 months and the performance period is 12 months. The first average correlation coefficient here is low, and the second is 


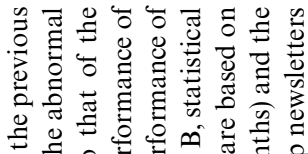
다월

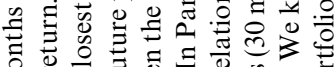

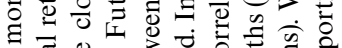
ปี

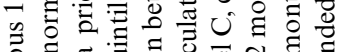

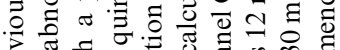

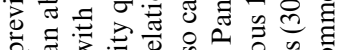

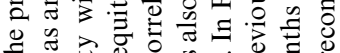

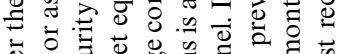

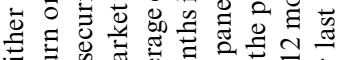

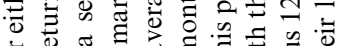

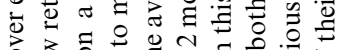

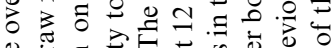
$\delta \sigma^{\circ} \Xi$

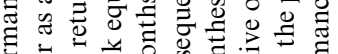

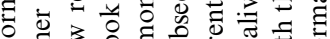

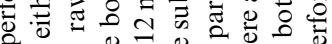

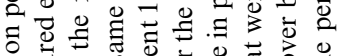
च जै 光

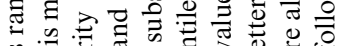
$\because \frac{0}{0}$

\&

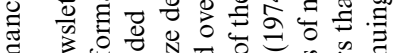

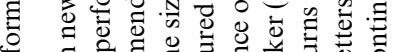

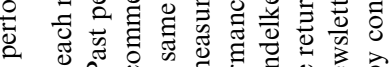
क $\approx$ o б

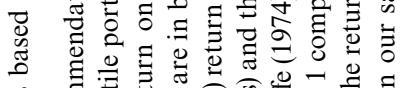

\% 局

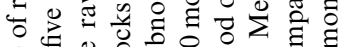

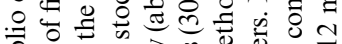

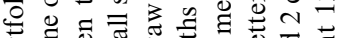

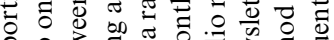
의 0

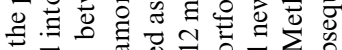
讨 o

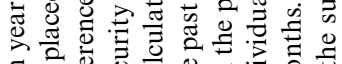

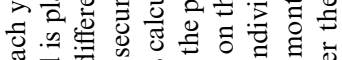
एँ $\overrightarrow{0}$ च

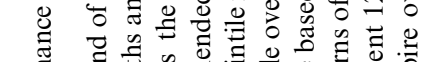

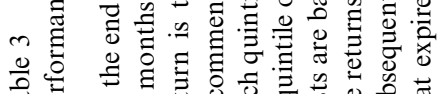

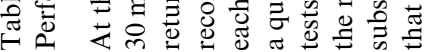

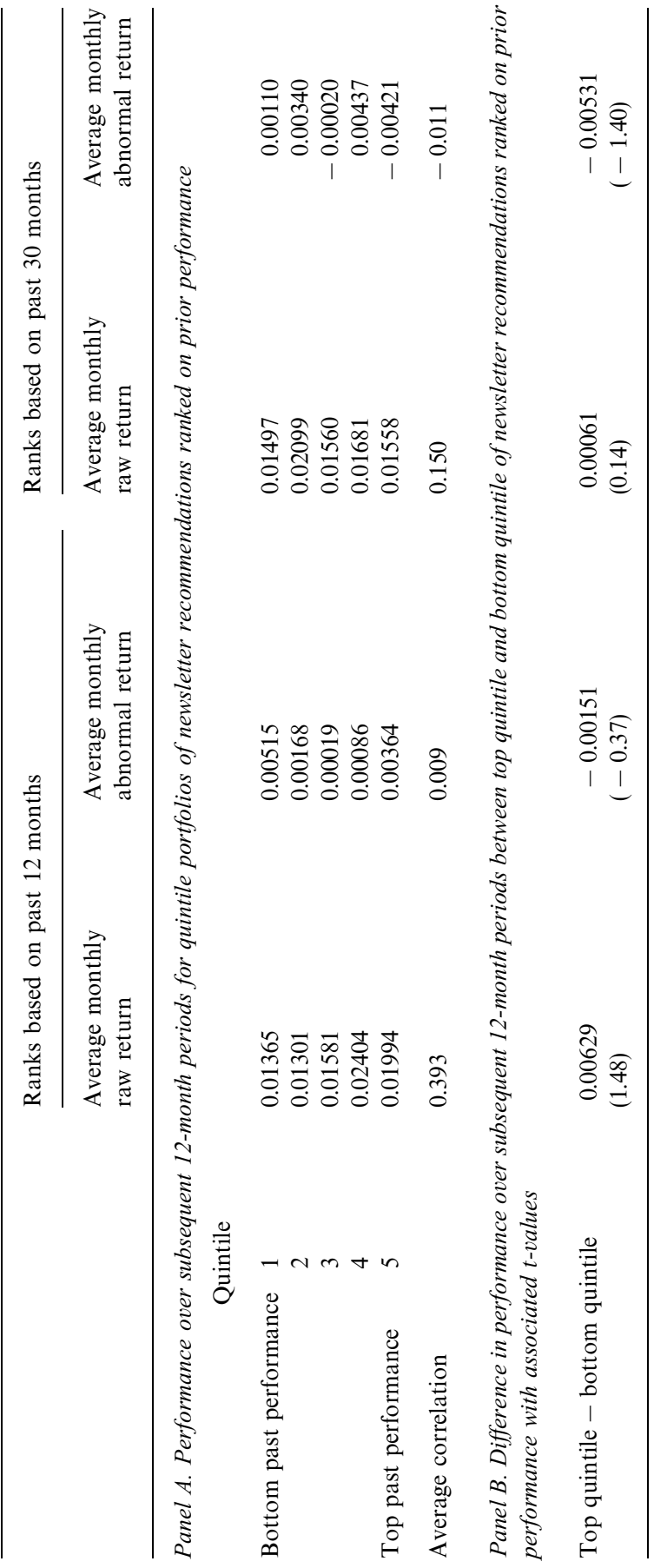




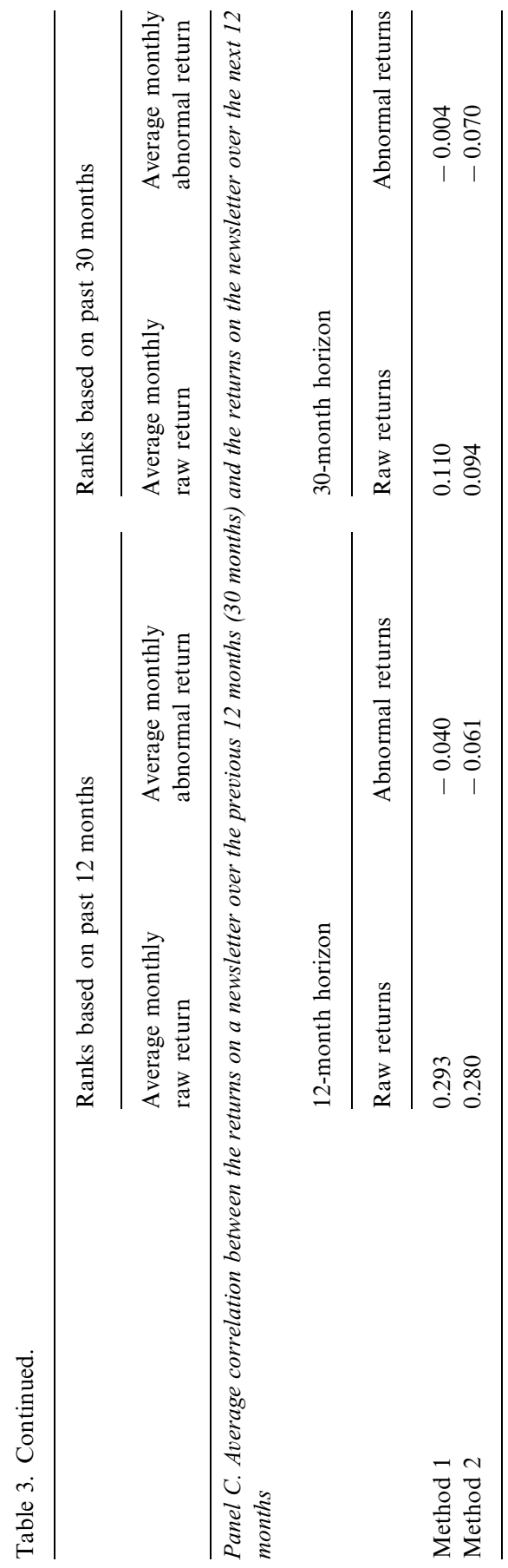


negative, indicating little evidence of persistence in either raw or abnormal returns.

Panel B provides a comparison of subsequent returns between the extreme quintiles. We measure statistical significance using the portfolio approach explained in Section 3. The four differences in subsequent performance shown in the panel are all statistically insignificant. As we move through a calendar year, newsletters may drop out of our sample. In a number of cases, particularly earlier in our sample period, a quintile may have no newsletters remaining at the beginning of a particular month. We calculate the return on quintile 5 minus the return on quintile 1 only in those months with at least one newsletter remaining in each quintile at the beginning of the month. This causes no hindsight bias, since this rule can be implemented in practice. The difference in returns between the top quintile and the bottom quintile in Panel B will not equal the difference between the extreme quintiles in Panel A.

Finally, the average correlation between the returns on a newsletter over the past 12 months ( 30 months) and the returns on the newsletter over the next 12 months appears in Panel C. Method 1 compares the returns of newsletters that were alive over both the previous 12 months (30 months) and the subsequent 12 months. Since a hindsight bias may arise with Method 1, Method 2 compares the returns of newsletters that were alive over the previous 12 months (30 months). We keep newsletters that expire over the subsequent 12 months in our sample by continuing to follow the performance of their last recommended portfolio. The correlation coefficients in the first column of Panel C are high, but the coefficients in the third column are lower, suggesting mixed evidence of persistence in raw returns. Since all four coefficients in the second and fourth columns are low and negative, we find no evidence of persistence in abnormal returns.

Taken together, all three panels show only modest evidence of persistence in raw returns and no evidence of persistence in abnormal returns.

\section{Herding and feedback}

A number of recent papers, such as Lakonishok et al. (1992a) and Grinblatt et al. (1993), have examined the cross-sectional dependence of trading by institutional investors. Our dataset allows us to investigate the same issue for investment newsletters. We use the following measure of herding in a particular month for an individual stock $i$, originally proposed by Lakonishok et al. (1992a, p. 29):

$$
H(i)=\left|\frac{B(i)}{(B(i)+S(i))}-p(t)\right|-A F(i)
$$


where $B(i)$ is the number of investment newsletters that add to their positions in stock $i$ in a particular month, $S(i)$ is the number of newsletters that reduce their positions in stock $i$, and $p(t)$ is the average proportion of newsletters that are net purchasers across all stocks in that month relative to the number that are active. Of course, because of the absolute value sign, the expected value of the first term on the right-hand side (RHS) of Eq. (3) must be positive. Thus, Lakonishok et al. introduce an adjustment factor, $A F(i)$, to set $E(H(i))=0 . A F(i)$ is the expected value of the first term on the RHS of Eq. (3) under the null hypothesis of no herding.

Because of $A F(i)$, the adjustment factor, $E(H(i))$ for any stock-month should be zero in a world with no herding. $E(H(i))$ should be positive (negative) in a world with herding (negative herding). Negative herding implies that a newsletter is more likely to recommend purchases (sales) in a particular stock-month if other newsletters are recommending sales (purchases).

Table 4 presents the results of our tests for herding. The first column in Panel A provides median and mean values for $H(i)$ across all stock-months in which at least two newsletters are active. ${ }^{2}$ The $t$-value is calculated assuming independence across stock-months. While the $t$-value is strongly significant, the magnitude is small. The mean value of 0.0359 is of the same order of magnitude as the mean value of 0.027 reported by Lakonishok et al. (1992a, Table 2), who conclude that there is only weak evidence of herding. Thus, newsletters seem to have about the same low propensity for herding as money managers. We also reran Table 4 so that each individual portfolio within a newsletter, rather than the equal-weighted combination of each newsletter's portfolios, was treated separately, and the mean and the median values were much higher. Of course, this is to be expected, since the different portfolios of one newsletter are likely to have many recommendations in common.

The next column shows herding for stock-months in which at least three newsletters are active. While the $t$-value of 2.61 is still significant, the mean here is lower, at 0.0185 . In addition, the median is 0.0 , a statistic providing no evidence of herding.

Next, at the end of each month, all securities on the NYSE are placed into one of five quintiles based on market capitalization. For each quintile, we calculate $H(i)$ for each stock-month in which two or more newsletters were active. The statistics are reported in Panel B of Table 4. The means are positive for each of the five quintiles, with significant $t$-values for quintiles $2-4$. The mean is insignificantly different from zero for the largest securities, the quintile with the greatest

\footnotetext{
${ }^{2}$ Our study uses herding statistics to measure the cross-sectional dependence of recommendations across newsletters. Since stock-months in which only one newsletter is active cannot be informative concerning cross-sectional dependence, we ignore all such stock-months.
} 
Table 4

Herding measurements for individual stock-months for newsletters over period

This table presents herding statistics for our sample of newsletter stock recommendations when at least a minimum number of newsletters is active in a particular stock-month. For each stock-month, we calculate the statistic $H(i)=|B(i) /(B(i)+S(i))-p(t)|-A F(i) . B(i)$ is the number of investment newsletters that add to their positions in stock $i$ in a particular month, $S(i)$ is the number of newsletters that reduce their positions in stock $i, p(t)$ is the average proportion of newsletters that are net purchasers across all stocks in that month relative to the number that are active, and $A F(i)$ is the adjustment factor such that $E(H(i))=0$ in a world without herding. Means and medians are calculated across all stock-months. $t$-statistics, which are in parentheses, assume independence across stock-months. In Panel B, breakpoints for size-quintiles are determined from NYSE securities alone.

Panel A. Herding statistics for the entire sample

At least two newsletters active

At least three newsletters active

\begin{tabular}{lcc}
\hline Median & 0.0457 & 0.0000 \\
Mean & 0.0359 & 0.0185 \\
$t$-value & $(11.01)$ & $(2.61)$ \\
$N$ (stock-months) & 4229 & 829
\end{tabular}

Panel B. Herding statistics for stocks in size-quintiles where at least two newsletters are active in the same stock-month

\begin{tabular}{lllllc} 
& $\begin{array}{l}\text { Quintile 1 } \\
\text { (Smallest) }\end{array}$ & 2 & 3 & 4 & \multicolumn{1}{c}{\begin{tabular}{c} 
(Largest) \\
\cline { 2 - 6 } Median
\end{tabular}} \\
\cline { 2 - 6 } & 0.00 & 0.00 & 0.00 & 0.00 & -0.0073 \\
Mean & 0.0140 & 0.0299 & 0.0343 & 0.0323 & 0.0009 \\
-value & $(0.91)$ & $(2.68)$ & $(3.90)$ & $(4.04)$ & $(0.67)$ \\
& 47 & 336 & 528 & 847 & 2447 \\
\hline
\end{tabular}

sample size. In addition, the medians are zero for the first four quintiles and actually negative for the fifth. Thus, Panel B provides little evidence of herding.

The previous table examines the cross-correlation of stock recommendations among newsletters. It is also interesting to investigate the determinants of these recommendations. While a full-blown model is beyond the scope of this paper, Table 5 investigates whether newsletters base their selections, at least in part, on past performance.

To assess sentiment for buying or selling in a particular month, we calculate the following ratio, first suggested by Lakonishok et al. (1992a), for each stock $i$ :

$$
N_{\text {ratio }}(i)=\frac{B(i)}{B(i)+S(i)}
$$


Table 5

Purchase and sale recommendations of newsletter for stocks based on size and past performance

For each stock, $N_{\text {ratio }}(i)=$ \# buys $(i) / \#$ active $(i)$ is calculated for each month, where \# buys $(i)$ is the number of newsletters recommending an increase in the holding of stock $i$ in a particular month and \# active $(i)$ is the number of newsletters recommending a change in the holding of stock $i$ in a particular month. At the beginning of each month, quintiles are formed based on either raw returns or abnormal returns over the past quarter. The abnormal return for a newsletter is the difference between the return on its portfolio of recommended stocks and the return on its control portfolio. The first line in each cell calculates the average value of $N_{\text {ratio }}(i)$ across all stock-months in which at least one newsletter is active. The second line in parentheses calculates the standard error of this value, assuming observations are independent across months.

\begin{tabular}{|c|c|c|c|c|c|}
\hline Ranking & 1 (Worst) & 2 & 3 & 4 & 5 (Best) \\
\hline Raw return over past quarter & $\begin{array}{c}0.2868 \\
(0.0088)\end{array}$ & $\begin{array}{c}0.3867 \\
(0.0080)\end{array}$ & $\begin{array}{c}0.4505 \\
(0.0079)\end{array}$ & $\begin{array}{c}0.5373 \\
(0.0068)\end{array}$ & $\begin{array}{c}0.6312 \\
(0.0051)\end{array}$ \\
\hline Abnormal return over past quarter & $\begin{array}{c}0.4536 \\
(0.0144)\end{array}$ & $\begin{array}{c}0.4560 \\
(0.0082)\end{array}$ & $\begin{array}{c}0.4920 \\
(0.0043)\end{array}$ & $\begin{array}{c}0.5675 \\
(0.0073)\end{array}$ & $\begin{array}{c}0.6096 \\
(0.0117)\end{array}$ \\
\hline
\end{tabular}

where $B(i)$ is the number of newsletters recommending an increase in the holding of stock $i$ in a particular month, and $S(i)$ is the number of newsletters recommending a decrease in the holding of stock $i$ in a particular month.

We then measure this ratio for groups of stocks formed as follows. At the end of each month, we rank all common stocks in CRSP by either raw returns or abnormal returns over the previous quarter, and, for each ranking, we place the stocks into five quintiles. As previously calculated in this paper, breakpoints are based only on stocks listed on the NYSE. Thus, the two rankings produce ten cells in Table 5.

For each cell in the table, the first line calculates the average value of $N_{\text {ratio }}(i)$ across all stock-months in which at least one newsletter is active. The second line calculates the standard error of this value, assuming observations are independent across months. For both measures of past performance, the average value of $N_{\text {ratio }}$ increases with past performance. This pattern indicates that newsletters are more (less) likely to recommend past winners (losers).

\section{Survivorship}

Common sense suggests that firms producing good products are more likely to prosper than firms producing bad products. One can expect newsletters with good track records to increase their customer base and continue publishing and newsletters with bad track records to lose their customer base and, perhaps, cease publishing. Yet, our earlier results suggest no evidence of persistence in 
Table 6

Logit models of survivorship

The table presents the results of the following pooled time-series/cross-sectional logit regressions:

$$
\operatorname{Prob}\left(T E R M I N A T E_{\tau}=1\right)=\frac{1}{1+\mathrm{e}^{-\left(\beta_{0}+\beta_{1} R A W_{\tau}-1+\beta_{2} Y R S A L I V E_{\tau}-1\right)}},
$$

where TERMINATE $\tau$ is equal to 1 is the newsletter ceases to publish in year $\tau$ and is equal to 0 if the newsletter survives throughout the entire year. $R A W_{\tau-1}$ is the raw return on the newsletter's portfolio over the 12-month period ending at the end of year $\tau-1$. YRSALIVE $E_{\tau-1}$ is the time between the first date for which we have data on a particular newsletter's recommendations and the end of year $\tau-1$. Our dataset on the dependent variables runs from 1982 to 1996 . There are 845 observations, i.e., newsletter-years, in all regressions. Numbers in parentheses are $p$-values.

\begin{tabular}{lccc}
\hline Regression & Intercept & $R A W$ & YRSALIVE \\
\hline$(1)$ & -2.4196 & -17.9566 & \\
& $(0.0001)$ & $(0.0224)$ & \\
$(2)$ & -3.1140 & -14.4713 & $(0.2241$ \\
& $(0.0001)$ & $(0.0466)$ & $(0.0019)$ \\
\hline
\end{tabular}

performance, when performance is measured by abnormal returns. One can, therefore, alternatively anticipate no relationship between past performance and future survival.

To test these two opposing hypotheses, we relate survivorship to past performance. Our basic results appear in Table 6, which provides two pooled time-series/cross-sectional logit regressions. In these regressions, the dependent variable is equal to 1 if the newsletter dies sometime in year $\tau$ and is equal to 0 if the newsletter survives throughout the entire year.

We relate the probability of failure to $R A W_{\tau-1}$, which is the raw return on the newsletter's portfolio over the 12-month period ending at the end of year $\tau-1$. We also include YRSALIVE $E_{\tau-1}$, which is the time between the first date for which we have data for a particular newsletter's recommendations and the end of year $\tau-1$. For this variable, time is measured in years or a fraction thereof.

In both regressions in Table 6 , the coefficients on $R A W$ are negative with low $p$-values. In addition, we ran (but do not report) regressions in which the abnormal return and return relative to the Standard and Poor's 500 Index replace raw returns. The coefficients are also negative for these regressions, and the $p$-values are even lower. We therefore conclude that there is a strong positive relationship between survivorship and past performance, a result consistent with that of Graham and Harvey (1996) on market-timing newsletters.

The coefficient on YRSALIVE is significantly negative in the last regression. This result is sensible, since older, more established newsletters should be more resistant to failure following a bout of poor performance. 


\section{Conclusions}

While there is a large literature on the investment performance of mutual funds and other financial vehicles, there has been little work on the performance of investment newsletters. Our paper examines the recommendations of common stocks made by the investment newsletters followed by the Hulbert Financial Digest.

We find that the median number of recommended stocks per newsletter is generally between 10 and 16 . The recommendations of the average newsletter have an annual turnover between 4.83 and 8.29 over our sample period. The average beta across newsletter recommendations is slightly greater than 1 . The average size decile across newsletter recommendations is 6.16 , while the valueweighted average of the size deciles across all stocks on the NYSE, AMEX, and NASDAQ is much higher, at 8.9. We also find that newsletters tend to recommend stock with low book-to-market ratios.

We find no evidence that, taken as a whole, the securities that newsletters recommend outperform the control firms. In addition, we examine the persistence of newsletter performance. We find modest evidence that the future performance of a newsletter is related to its past performance, when performance is measured by raw returns, but evidence of persistence vanishes when performance is measured by abnormal returns. We therefore conclude that the performance of newsletters does not exhibit persistence.

We examine the cross-sectional dependence of newsletter recommendations. We find little, if any, evidence of herding among newsletters. Newsletters do tend to recommend securities that have performed well in the past. Finally, we find that survivorship is positively related to both past performance and age.

Our most striking findings concern investment performance. The inability of newsletters to beat market averages is consistent with research on mutual funds, yet mutual funds allow small investors to achieve low-cost diversification. While we find no evidence of persistence in abnormal returns for newsletters, the literature on mutual funds and pension funds is more mixed. For example, Gruber (1996, p. 807) concludes that '[f]uture performance is in part predictable from past performance' for mutual funds. Lakonishok et al. (1992b) also find some evidence of persistence in the performance of pension funds.

\section{References}

Barber, B.M., Lyon, J.D., 1997. Detecting long-run abnormal stock returns: the empirical power and specification of test statistics. Journal of Financial Economics 43, 341-372.

Brealey, R., Myers, S., 1996. Principles of Corporate Finance. McGraw-Hill, New York.

Carhart, M.M., 1997. On persistence in mutual fund performance. Journal of Finance 52, 57-82.

Graham, J.R., Harvey, C.R., 1997. Market timing ability and volatility implied in investment newsletters' asset allocation recommendations. Journal of Financial Economics 42, 397-421. 
Grinblatt, M., Titman, S., Wermers, M., 1993. Momentum strategies, portfolio performance and herding: a study of mutual fund behavior. American Economic Review 85, 1088-1105.

Gruber, M.J., 1996. Another puzzle: The growth in actively managed mutual funds. Journal of Finance 51, 783-810.

Jaffe, J.F., 1974. Special information and insider trading. Journal of Business 47, 410-428.

Lakonishok, J., Shleifer, A., Vishny, R.W., 1992a. The impact of institutional trading on stock prices. Journal of Financial Economics 32, 23-44.

Lakonishok, J., Shleifer, A., Vishny, R.W., 1992b. The structure and performance of the money management industry. Brookings Papers on Economic Activity: Microeconomics, pp. 339-379.

Mandelker, G., 1974. Risk and return: the case of merging firms. Journal of Financial Economics 1, 303-335. 